Res., Soc. Dev. 2019; 8(5):e1385702

ISSN 2525-3409 | DOI: http://dx.doi.org/10.33448/rsd-v8i5.702

\title{
Como a família lida com a dificuldade da criança diante do baixo rendimento escolar?
}

How the family deals with the child's learning difficulty in the face of his/her poor school performance?

¿Cómo la familia maneja la dificultad del niño frente al bajo rendimiento escolar?

\section{Rosa Maria da Motta Azambuja}

ORCID: https://orcid.org/0000-0002-2531-6664

Universidad de la Empresa, Uruguay

E-mail: psicoazambuja@hotmail.com

Recebido: 28/10/2018 | Revisado: 03/12/2018 | Aceito: 26/02/2019 | Publicado: 27/02/2019

\section{Resumo}

O artigo objetiva analisar como a família lida com a dificuldade da criança diante do baixo rendimento escolar. Realizou-se um estudo de caso em uma escola particular de uma comunidade de camada popular da cidade do Salvador cujo projeto foi submetido e aprovado pelo Comitê de Ética em Pesquisa. Participaram do estudo três crianças, duas estudantes de sete e oito anos de idade, do segundo ano e um estudante de sete anos de idade, do primeiro ano do Ensino Fundamental, juntamente com seus pais. Realizou-se a análise da interação pais e filhos a partir de instrumentos da teoria sistêmica da família (jogo colaborativo e genograma). Identificou-se que as crianças manifestam vínculos familiares característicos de dependência; que as práticas educativas parentais são transmitidas através de um modelo autoritário com maior controle, regras impostas, pouco apoio à criança, muita exigência e pouco afeto; que as estratégias utilizadas para orientar o comportamento dos filhos são caracterizadas pela aplicação direta da força, incluindo punição física ou uso de ameaças. Além disso, a pesquisa aponta a qualidade da escola, a baixa escolaridade dos pais e o convívio em bairro violento como fatores que podem interferir na dificuldade de aprendizagem e que, portanto, necessitam ser melhor investigados em estudos futuros.

Palavras-chave: Criança; Relações familiares; Dificuldade de aprendizagem.

\begin{abstract}
This article aims to study takes as its object the family ties of children with poor academic performance by adopting a relational perspective, which enables the observation of the family as a subject that is likely to establish meaningful relationships among its members. In order to
\end{abstract}


analyze how the family deals with the child's learning difficulty in the face of his/her poor school performance, a case study was performed in a private school located in a lowermiddle-class community in the city of Salvador, whose project was submitted and approved by the Committee of Ethics in Research. Three children took part in the study; two female students, at the age of seven and eight years, who study at the Second Grade of Elementary School, and one male student, at the age of seven, studying at the First Grade of ES; along with their parents. From the basic question, concerning the way parents deal with their children's difficulty of learning, two procedures were held: the assessment of the children's learning, using instruments from Visca's convergent perspective and, then, the analysis of the parent-child interaction, with instruments from the systems theory of the family (collaborative game and genogram). It was found that the children express family bonds characteristic of dependence; that the parental educative practices are conveyed through an authoritarian model with greater control, imposed rules, little support for the child, a lot of demand and lack of affection; that the strategies used by the parents to guide their children's behavior are characterized by the direct use of force, including physical punishment or the use of intimidation; ultimately, it was found that the present methods for teaching and learning restrict the development of learning because they reduce the child's spaces of choice. In addition, the research demonstrates the quality of the school, the low parental academic education and living in a violent neighborhood as factors that may interfere with learning difficulty and that, therefore, have to be better investigated in future studies.

Keywords: Children; Family relationships; Learning difficulty

\section{Resumen}

El artículo objetiva analizar cómo la familia maneja la dificultad del niño frente al bajo rendimiento escolar. Se realizó un estudio de caso en una escuela particular de una comunidad de capa popular de la ciudad del Salvador cuyo proyecto fue sometido y aprobado por el Comité de Ética en Investigación. En el estudio participaron tres niños, dos estudiantes de siete y ocho años de edad, del segundo año y un estudiante de siete años de edad, del primer año de enseñanza primaria, junto con sus padres. Se realizó el análisis de la interacción padres e hijos a partir de instrumentos de la teoría sistémica de la familia (juego colaborativo y genograma). Se identificó que los niños manifiestan vínculos familiares característicos de dependencia; que las prácticas educativas parentales se transmiten a través de un modelo autoritario con mayor control, reglas impuestas, poco apoyo al niño, mucha exigencia y poco afecto; que las estrategias utilizadas para orientar el comportamiento de los hijos se 
caracterizan por la aplicación directa de la fuerza, incluyendo punición física o uso de amenazas. Además, la investigación apunta la calidad de la escuela, la baja escolaridad de los padres y la convivencia en barrio violento como factores que pueden interferir en la dificultad de aprendizaje y que, por lo tanto, necesitan ser mejor investigados en estudios futuros.

Palabras clave: Niño; Relaciones familiares; Dificultad de aprendizaje.

\title{
1. Introdução
}

A família é o grupo primário ao qual a criança pertence segundo uma dinâmica que favorece vínculos particulares que irão interferir na formação da sua identidade. Para além de elementos determinados geneticamente, o desenvolvimento da identidade requer a interação das relações familiares com aspectos socioculturais, que se formam de acordo com a história de aprendizagem da criança no âmbito familiar.

A reflexão de pensadores como Pierpaolo Donati representa uma concepção de família e de vínculo social que integra um novo paradigma denominado "relacional" a explicitar, sistematizar e aprofundar aspectos já presentes em obras de autores brasileiros e italianos que investigam as relações familiares. Na perspectiva relacional, a família é entendida como rede de solidariedade e fonte de recursos importantes para a formação da pessoa e da sociedade, com grande repercussão na constituição de práticas solidárias nos diversos ambientes.

\begin{abstract}
A abordagem relacional pega o melhor de cada abordagem, quer teórico, quer prático, e procura exprimi-las de uma maneira que funcione. A abordagem relacional não é sincrética, tenta ir ao coração da família no sentido de reconhecer a peculiaridade, a originalidade da relação familiar, como diferente de todas as outras relações (DONATI, 2008, p. 23).
\end{abstract}

Essa abordagem se revela fecunda no estudo de diferentes subsistemas da sociedade complexa, tendo já apresentado resultados especialmente significativos nas pesquisas em família bem como na intervenção de operadores sociais neste campo. O autor toma como chave interpretativa da sociedade nos seus diversos aspectos e dimensões a relação social que se estabelece entre sujeitos humanos ao interagirem nas diversas circunstâncias da vida. Afinal, o que é relação social? O que significa estar em relação com outras pessoas? O que se quer dizer com os fatos sociais são realidades relacionais?

Fundamentando-se na teoria sociológica de autores diversos, dentre os quais Marcel Mauss (1974), Donati entende que toda relação implica em uma troca não somente de tipo 


\title{
Res., Soc. Dev. 2019; 8(5):e1385702 \\ ISSN 2525-3409 | DOI: http://dx.doi.org/10.33448/rsd-v8i5.702
}

econômico. Na relação, tem origem uma ação recíproca entre sujeitos sociais que geram ou atualizam um vínculo que pode ser percebido e experimentado como recurso ou como amarra.

[...] Podemos dizer que a relação social é aquela referência - simbólica e intencional - que conecta sujeitos sociais na medida em que atualiza ou gera um vínculo entre eles, isto é, enquanto expressa sua 'ação recíproca'. Esta consiste na influência que os termos da relação têm um sobre o outro e no efeito de reciprocidade emergente entre eles (DONATI, 2008, p. 25).

Justificando esse ponto de vista, o autor considera que se trata de tomar como objeto de estudo sociológico a própria relação social na sua contingência e variabilidade, na capacidade que tem de estabelecer vínculos, construí-los ou dissolvê-los, convergindo com outros para realizar algum tipo de intercâmbio, para cooperar ou para conflitar-se. No aspecto de convergência com o outro, Donati insere a abordagem relacional da família:

\begin{abstract}
A perspectiva relacional é um modo de conhecer e um modo de intervir sobre a família, que abre uma nova perspectiva de estudo, pois constitui uma abordagem teórica, uma nova maneira de conhecer a família, ou melhor, reconhecê-la nas suas características, nos seus fatores constitutivos. Mas, ao mesmo tempo, tem utilidade operativa para planejar e realizar intervenções na realidade familiar quer no plano das políticas sociais, nacionais e supranacionais, quer no nível micro, através do atendimento a famílias portadoras de necessidades (2008, p. 27).
\end{abstract}

Nesse sentido, focalizar a atenção sobre a família como relação permite contemplar diversas dimensões. A teoria relacional propõe um modo de observar a família, avaliar a situação e intervir, segundo um método que priorize o olhar sobre as relações, pois os problemas da família nascem nas relações e não nos indivíduos e implicam comportamentos e reações individuais (DONATI, 2008). O autor justifica que a observação torna possível identificar como são organizadas as relações familiares.

Somente se pode compreender e avaliar a família em razão da sua própria origem, assim, o modo como é gerada e o modelo constituído são os pontos iniciais do estudo sobre as relações familiares. $\mathrm{Na}$ atualidade, as relações entre pais e filhos ganham relevo (PETRINI, 2007; SINGLY, 2007; DONATI, 2008), pois se organizam sob novas pautas, com o abandono da forte assimetria e hierarquização com modelos centrados na autoridade e na disciplina (SAMARA, 2002), enquanto foram incorporadas novas práticas baseadas no diálogo, na negociação, tolerância, no horizonte de um amplo pluralismo ético e democrático (BIASOLIALVES; SIMIONATO-TOZO; SAGIM, 2006).

Nesse aspecto, Petrini aponta algumas mudanças intergeracionais que ocorreram na família nas últimas décadas: 


\begin{abstract}
As novas gerações divergem da geração dos adultos e dos avós, quanto às metas que merecem ser perseguidas, aos critérios para discernir o que vale ou o que deve ser descartado. As novas gerações experimentam, muitas vezes, uma distância e uma estranheza com relação aos pais e à geração mais velha em geral. No quotidiano, prevalece a busca pela maior acomodação e o diálogo é substituído por negociações pontuais. Os vínculos que ligam avós, pais e filhos, tendem, nesse ambiente, a se modificar (2007, p. 209).
\end{abstract}

Os vínculos de pertença, que ligam os pais aos filhos e vice-versa, tendem, nesse ambiente, a ser mais frouxos e as relações intergeracionais tendem a modificar-se no sentido de distanciamento dos vínculos intergeracionais. Todavia, Scabini e Cigoli (2007) propõem uma nova forma de refletir acerca das gerações como uma ampla reflexão não determinística para as gerações seguintes, um pensamento marcado pela liberdade, e, em função disto, pelo risco, seja da parte de quem oferece como de quem recebe o patrimônio cultural veiculado.

A palavra vínculo é derivada do latim vinculum, raiz etimológica vincer que significa "união, nó, laço ou ligadura de uma coisa a outra". Usa-se como expressão duradoura de estar com o outro.

A esse respeito, Berenstein (2002) faz referência ao vínculo na família como "o eixo central que sustenta o estar com os outros". Portanto, a estrutura vincular só pode ser conhecida pelos sujeitos através da pertença, que significa e designa um lugar a ser ocupado pelo sujeito na estrutura vincular do conjunto. Desta maneira, transita-se de um pensar identitário a um pensar em vínculo no qual o fazer com os outros tem um lugar fundamental. Este fazer se produz no presente: trata-se de presentações, isto é, de novidades que se dão a partir desse "entre nós" enquanto presenças e que só surgem da experiência subjetiva vincular.

Em uma perspectiva interpessoal, Carvalho, Politano e Franco (2007) apontam o conceito de vínculo na teorização psicológica, remetendo a Bowlby (2002), que concebe o vínculo mãe-filho/adulto-cuidador de criança, denominado apego (attachment), como uma adaptação fundamental da espécie humana, uma necessidade tão primária quanto a satisfação da fome ou da sede e justificam essa necessidade e os mecanismos pelos quais se realiza na ontogênese, que teria sido criada no decorrer da evolução humana em função da importância da proximidade com o adulto para a proteção e o desenvolvimento da criança, que nasce em condições de absoluta dependência de cuidados do outro e de adaptação básica. $\mathrm{O}$ apego é um processo de estabelecimento que se inicia, possivelmente, já na vida intrauterina e vai se manifestar em termos comportamentais, podendo ser compreendido como o conjunto de comportamentos do bebê que se caracteriza não somente pela busca de proximidade física da 
mãe, mas, também, pela exploração do ambiente. (CARVALHO, 2005; CARVALHO; et al., 2006).

Nesse sentido, Bowlby (1993) revela que o apego do bebê à mãe constitui o fundamento para uma base segura a partir da qual o bebê pode explorar o mundo e experimentar outras relações, analisa o relacionamento pais-bebês e diferencia o comportamento de apego daquele do vínculo afetivo. O sentimento do bebê em relação a seus pais é apego, na medida em que ele sente nos pais a base segura para explorar e conhecer o mundo à sua volta. O sentimento dos pais em relação ao filho é mais corretamente descrito como vínculo afetivo, já que os pais não experimentam um aumento do seu senso de segurança na presença do filho e tampouco o filho tem para os pais a característica de base segura. $\mathrm{O}$ vínculo nos remete a uma relação simbólica e estrutural que liga as pessoas entre si em um projeto de vida, entrelaçando-as em uma dimensão horizontal (a do casal) e uma dimensão vertical (a descendência e a ascendência) que supõem a geração e a educação de filhos (PETRINI, 2003).

Na dimensão vertical, a família proporciona condições para que a criança seja acolhida e amada desde quando ainda no ventre materno e, em seguida, nas diversas etapas do seu desenvolvimento até a maturidade. Ela experimenta a positividade de pertencer a pai e mãe não como um objeto, mas, como pessoa, no respeito e no diálogo, em contexto afetivo.

Podemos, então, perguntar precisamente: qual é o papel dos pais nessa fase de desenvolvimento dos filhos? Essa tarefa é a de tomar conta, de forma responsável, dos filhos (CIGOLI; SCABINI, 2006; SCABINI; CIGOLI, 2007), um papel que é denominado "cuidado responsável" em que o termo cuidado remete à qualidade afetiva dos vínculos, enquanto responsabilidade se refere, principalmente, à ética.

Na perspectiva relacional simbólica estrutural, os vínculos familiares são vistos a partir de dois de seus eixos característicos: afetividade e ética. A família, de fato, é o lugar dos afetos mais profundos assim como das responsabilidades mais rigorosas. Para os autores, a expressão “cuidado responsável” exprime a função parental.

Refletindo sobre essa expressão, “cuidado responsável”, surgem as questões: O que exprime a função parental? O que quer dizer tomar conta responsavelmente dos próprios filhos, de modo concreto? O que os pais garantem aos filhos, de maneira privilegiada e incondicional?

Em pesquisa sobre o desenvolvimento humano, Cigoli e Scabini (2006) entendem que o cuidado responsável que os pais exercem ao lidar com os filhos se expressa em dois níveis: na garantia da confiança, afeto (polo afetivo), mas, também, na transmissão do 
pertencer, em dar direção ao crescimento, encorajar o impulso emancipatório dos filhos, o que implica, necessariamente, o saber e o querer dar regras (polo ético). Vale a pena precisar que, apesar de a dimensão afetiva do cuidado e do sustento se referir, cultural e simbolicamente, à figura materna e a ética do compromisso e orientação, à figura paterna, na realidade, o cuidado responsável representa uma tarefa conjunta da qual ambos os genitores devem se encarregar, mesmo na diversidade e especificidade de seus papéis.

É fundamental que os pais saibam garantir ao(s) filho(s) ambos os aspectos do cuidado - afeto e regras - visto que o empobrecimento ou, até mesmo, a falta de um ou de outro aspecto, comporta riscos para o crescimento. Afeto e regras não constituem, portanto, escolhas alternativas e inconciliáveis; representam os dois polos da relação educativa, o que vem significar que os pais são chamados diariamente a redefinir o seu pacto parental e a recompor sempre um novo e mais adequado equilíbrio entre as dimensões afetivas e éticas que qualificam os vínculos familiares. (SCABINI; IAFRATE, 2003).

$\mathrm{O}$ itinerário do vínculo pais-filhos segue essa trajetória não linear, mas dinâmica e integradora: dar a vida, cuidar, deixar caminhar (SCABINI; CIGOLI, 2007). Com esse percurso, se expressa bem a tarefa do adulto parental - que é chamado a construir um vínculo confiável com quem gerou - quanto a favorecer e promover o progressivo incentivo à aquisição de autonomia, que não deve ser aqui entendida como oposição, ruptura de vínculos ou independência reativa, mas diz respeito à atitude de responder por si mesmo, a partir do reconhecimento do próprio pertencer: uma boa combinação de senso de pertencimento e senso de unicidade (SCABINI, 2007).

Nesta pesquisa, que visa analisar como a família lida com a dificuldade da criança diante do baixo rendimento escolar, se constituiu de sessões de avaliação psicodiagnóstica, nas quais, além de levantar dados referentes à dificuldade de aprendizagem nas relações familiares foi possível identificar estratégias utilizadas pelos pais para lidar com a criança, comparar o resultado escolar antes e depois da avaliação psicopedagógica e divulgar esses dados para a família e a escola.

\section{Metodologia}

O estudo aconteceu em uma escola privada da cidade do Salvador - Bahia, localizada no bairro do Vale das Pedrinhas, que atende, nos turnos matutino e vespertino, a estudantes da Educação Infantil e do Ensino Fundamental, um público de classe popular residente em bairros periféricos próximos. A maioria dos pais participa ativamente dos eventos e das reuniões promovidas pela escola, demonstrando interesse pela vida escolar de seus filhos. 
Solicitou-se à Coordenação Escolar que indicasse cinco alunos com maior dificuldade de aprendizagem para participar do estudo. Os estudantes indicados foram três meninos e duas meninas entre sete e oito anos de idade, cursando o Segundo e o Terceiro anos do Ensino Fundamental. Os critérios de inclusão na amostra foram os seguintes: 1. Matrícula - estar matriculado na escola em 2011; 2. Ano Escolar - frequentar regularmente os anos iniciais do Ensino Fundamental; 3. Rendimento - apresentar baixo rendimento nas avaliações de todas as disciplinas; 4. Residência - residir próximo à escola; 5. Participação dos Pais - ter pais disponíveis a participar da coleta de dados. 6. Aceitação de Participação - Termo de Consentimento assinado pelos pais e/ou responsáveis.

Neste estudo, realizado por meio de entrevistas individuais com os pais e os filhos, no primeiro contato, colhe-se apenas a queixa inicial, sem entrar no histórico da criança (SAMPAIO, 2009); no segundo, aplica-se o instrumento "Jogo Colaborativo em Família" (FARIA, 1998) que possibilita analisar as relações vinculares no contexto familiar através da interação lúdica entre pais e filhos; no terceiro, em que se entrevista os pais, optou-se pelo roteiro de entrevista (CHAMAT, 2004) e pelo genograma familiar (CERVENY, 1994) sob a perspectiva psicopedagógica, com o fim de identificar repetições dos padrões intergeracionais entre a família de origem e a nuclear; o quarto contato consiste em comunicação verbal e escrita realizada para os pais e o aprendente.

Inicialmente, falou-se com a criança em uma linguagem compreensível e, em seguida, sem a sua presença, conversou-se com os pais. As entrevistas foram registradas e, posteriormente, transcritas pela pesquisadora, emergindo eixos interpretativos de análise. $\mathrm{O}$ relatório psicopedagógico seguiu o padrão proposto por Sampaio (2009).

Os resultados serão apresentados por meio desta análise interpretativa, centrada em dois eixos história original/genograma e Jogo colaborativo em família que farão o alinhavo analítico entre as questões macro e microssistêmicas.

\section{Resultados e discussão}

\section{A Menina Admirada ${ }^{1}$}

\footnotetext{
1 A fim de preservar o nome da criança participante, com base na Resolução 196/96, optou-se por identificá-la através de pseudônimo.
} 
O nome da criança que, em sua raiz etimológica, significa 'admirada', foi escolhido pela genitora quando assistia a um programa de TV. Prematura de oito meses apresentou baixo peso ao nascer. A genitora contribuiu para a nutrição do bebê, que se desenvolveu saudavelmente, e, conservando o hábito de facilitar a mastigação com alimento pastoso, ao introduzir a alimentação de grãos machucava-os até os dois anos de idade para auxiliar sua ingestão. Para Chamat (2004), Pichon-Rivière (2007) e Bleger (1988) essa atitude, reforça um modelo facilitador de aprendizagem.

Aos três anos de idade, ingressou na mesma escola da irmã com excelente adaptação social. Aos cinco anos, os pais se separaram e ela ficou residindo com o genitor, que desenvolveu hábitos dificultadores do desenvolvimento emocional da criança como dar banho, contar a mesma história sem alteração do enredo e dar a resposta para o dever de casa. Nos primeiros anos escolares, a criança manifestou agressividade e resistência em aprender. A coordenadora, sensibilizada com a situação familiar, promovia a aluna sem rendimento escolar (POLITY, 2004). Atualmente, a menina está na $2^{a}$ série e apresenta dificuldade de leitura e interpretação.

Na história de vida da "menina admirada" destacamos três aspectos relevantes: prematuridade; o modelo de aprendizagem facilitador dos pais; e o papel do pai na criação da filha.

O primeiro aspecto que notamos foi a gestação difícil seguida do parto cesariano e prematuro, aos oito meses. Autores como Muñiz (2001), Ramos e Cunha (2009) apontam que crianças cujas mães tiveram complicações na gravidez e/ou durante o parto ou que nasceram prematuras têm aumentada a possibilidade de desenvolvimento de algum tipo de dificuldade de aprendizagem.

O segundo aspecto observado é o modelo de aprendizagem facilitador desde as primeiras relações, que resta evidente no fato de a criança, com dois anos de idade, receber ainda alimentação triturada e se recusar a mastigar grãos. Esse tipo de atitude exemplifica a tendência a este modelo, segundo Chamat (2004), Pichon-Rivière (2007) e Bleger (1988), impede o rompimento do vínculo de dependência da criança dos genitores, do ponto de vista psicológico, afetivo-cognitivo e de comportamento infantilizado. "Falta-lhes esquemas e estruturas de pensamento que lhes possibilite uma aprendizagem assimilativa; e, ainda mais, o desejo de pensar pelo medo do desequilíbrio" (CHAMAT, 2004, p. 40).

O terceiro aspecto a ser considerado diz respeito ao papel do pai na criação da filha, após a separação da esposa. Para Bittelbrunn e Castro (2010), as pesquisas mostram a tendência de consolidação de um modelo paterno de atuação identificado como "novo pai" 
que ocupa um lugar, uma posição mais participativa e afetiva nas relações intrafamiliares, enfatizando a responsabilidade do homem não só no exercício da paternidade, mas, também, na divisão de tarefas domésticas, por meio da qual os homens cruzam a linha da demarcação de gênero (a tradicional divisão de papéis) a fim de expressar sua competência na paternidade solidária, no trabalho doméstico, seja por opção seja por necessidade. Porém, há um longo caminho para que essa competência solidária seja reconhecida, por ser ainda pouco discutida. Uma alternativa seria a quebra de barreiras existentes no imaginário social para o qual o feminino é sinônimo de cuidados filiais ou possui domínio único dentro da esfera familiar (BITTELBRUNN; CASTRO, 2010).

É importante salientar, no entanto, que o novo pai não exerce o cuidado sozinho. Em geral, ele conta com uma rede de apoio familiar, como confirmado pelas referidas autoras. No caso, o genitor, que reside no terreno de propriedade dos pais, tem o apoio da mãe e das irmãs no cuidado de suas filhas. Porém, ele conserva hábitos que dificultam a autonomia da filha no que diz respeito ao aprendizado.

\section{História da Genitora}

A.L nasceu no interior do estado da Bahia. Criada pela avó-materna, foi adotada aos sete anos de idade por um casal que teve doze filhos. Sendo a mais velha ajudou a criar os irmãos. Costumava fugir de casa ao perceber a sua mãe alcoolizada. Saiu do interior aos quinze anos para trabalhar como babá na Capital. Depois de muitos anos conheceu L.C., policial militar, resolveram morar juntos e tiveram duas filhas.

\section{História do Genitor}

C.L é o filho mais velho de três irmãos. Construiu no terreno dos pais umas peças e constituiu o seu lar. Herdando da genitora o conservadorismo, ele guarda o enxoval e o cordão umbilical das filhas. Esse era o motivo das discussões do casal: o hábito do marido guardar "quinquilharias" não ser compreendido pela esposa. O casal entrou em comum acordo e decidiu que a esposa e a filha iriam para o interior onde residia a família de A.L., para minimizar as brigas, e ele as visitaria em suas folgas de finais de semana. Meses depois retornaram para a capital porque a esposa estava grávida e com ameaça de aborto. Cinco anos depois, o casal se separou. 


\section{O Genograma Familiar}

O genograma (Figura 1) mostra a repetição da configuração familiar nuclear das famílias de origem (CERVENY, 1994; POLITY, 2004), especialmente no que tange ao comportamento do pai, neste caso, quanto a guardar o enxoval e o umbigo de sua filha, costume semelhante ao de sua própria mãe.
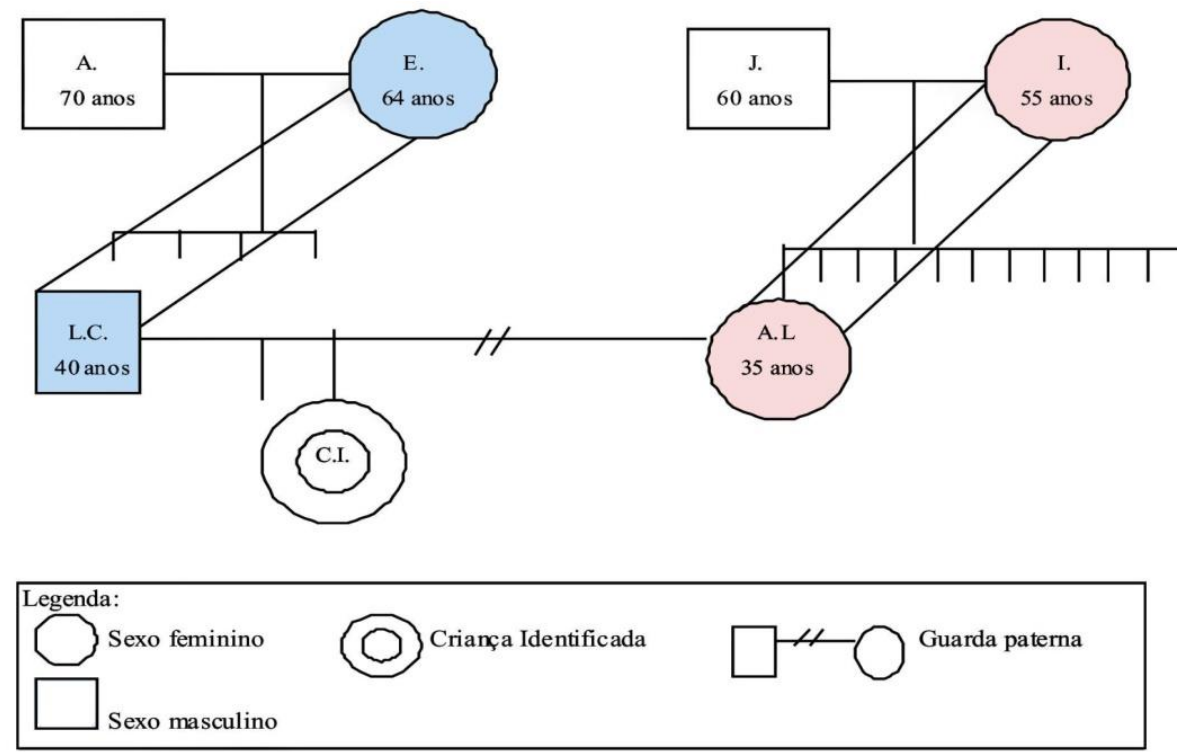

Figura 1 - Genograma Familiar: caso A Menina Admirada

Cerveny (1994) afirma que toda família transmite o seu modelo, como uma espécie de legado, e afirma que, não só os pais, mas todo o sistema familiar, estando aí incluídas as gerações passadas, servem como modelo para a transmissão de padrões comportamentais, que vão se repetir, podendo até pular alguma geração, mas ser encontrado novamente nas subsequentes. Para Polity (2004), essas repetições podem também ser observadas com relação à aprendizagem, pois o grupo familiar transmite o seu modelo, de forma que as gerações mais novas podem "aprender a aprender". No caso, o genitor conserva o hábito de ler as mesmas histórias para a filha antes de dormir. Segundo o pai, ele tenta modificar o enredo, porém a filha reclama e o pai cede.

Por outro lado, a genitora da criança relata que, devido aos constantes conflitos decorrentes do consumo de álcool por sua mãe, fugia da sua presença. De alguma maneira, a convivência conflituosa com a mãe foi incorporada como um modelo no exercício da maternidade de A.L. com sua filha, o que pode ter dificultado a formação de um vínculo estável. 
Em duas circunstâncias, houve uma situação similar, em que A.L. deixa sua casa: ao decidir ir para o interior morar na companhia da filha primogênita, sendo visitada esporadicamente pelo marido até engravidar e retornar para casa; e, atualmente, em que o casal é separado e as filhas residem com o genitor. Esse modelo evitativo continua se manifestando quando o ex-marido declara que ela tem dificuldade para procurar as filhas, que são as meninas que ligam para ela pedindo que as leve para passar o final de semana em sua casa.

Quando nos referimos à repetição de padrões intergeracionais de uma geração para outra subsequente, não nos colocamos na posição de que o passado determina, para o sistema atual, o que deve ser repetido. Nossa posição é que, no sistema relacional, estão disponíveis certos padrões que podem vir a ser repetidos por algum dos membros da família, conforme atesta Cerveny (1994, p. 42). Concordamos que os padrões intergeracionais se manifestam de diferentes formas. Existem sistemas familiares em que os padrões são repetidos exatamente como se deram na família de origem, como é o caso do genitor e, em outros sistemas, as repetições aparecem de forma camuflada e quase irreconhecíveis, como no caso da genitora. Mesmo assim, é possível compreender a força que as repetições têm no sistema familiar.

Durante a escuta, foi possível perceber um vínculo de dependência nas relações familiares observadas, fundamentadas em modelos de ensino improvisados, isto é, instaurados com base na experiência dos pais na sua família de origem, sem priorizar as características dos filhos nem a organização da família atual. Essa modalidade facilitadora dos pais tende a resultar na desorganização da criança, uma vez que deixa de promover sua autonomia.

Trata-se de crianças extremamente dependentes dos genitores, imaturas do ponto de vista psicológico e afetivo-cognitivo. Faltam-lhes esquemas de estruturas de pensamento que lhes possibilite uma aprendizagem assimilativa; e, ainda mais, o desejo de pensar pelo medo do desequilíbrio (CHAMAT, 1997).

A análise do jogo indica que os pais mantêm o vínculo de dependência e revela que eles não promovem o recurso às habilidades cognitivas que a criança possui, pois não entram em jogo com a filha. Aparentemente, "digerem" a informação sem estabelecer um diálogo que aprofunde o raciocínio e a compreensão da criança. Nesse caso, não aparece um vínculo saudável, mas uma dificuldade em lidar com o crescimento: o vínculo de dependência da criança com relação aos pais (CHAMAT, 1997).

Ao analisar as relações familiares procurando detectar que papéis os pais desempenham no processo do conhecimento na criança, Chamat (1997) concluiu que há 
predomínio do vínculo de dependência. Assim, cabe perguntar: Será que o vínculo de dependência não está interferindo na aprendizagem?

Encontramos em Lima (2002, p. 16), o seguinte comentário de Badinter (1985): “A criança deve passar pela fase edipiana e viver a perda da mãe para poder sublimar e substituir seu objeto de desejo, tendo assim, condições de aprender". Porém, através do Jogo Colaborativo em Família percebeu-se que os pais tendem a conservar a menina em uma fase de dependência, impedindo, a nível consciente ou inconsciente, sua passagem para uma nova fase.

\section{Considerações Finais}

O presente estudo teve como objetivo analisar como a família lida com a dificuldade de aprendizagem da criança diante do baixo rendimento escolar. Para isto, buscou-se identificar a modalidade de aprendizagem presente na interação entre pais e filhos em situação de ensino-aprendizagem e comparar o rendimento escolar da criança com dificuldade de aprendizagem antes e após a avaliação psicopedagógica.

A pesquisa possibilitou uma análise detalhada dos dados, a partir do diálogo com os participantes, atendendo, assim, aos objetivos que se propôs a investigar. Evidenciou-se que os relacionamentos familiares interferem na aprendizagem dos filhos, estimula-os a procurar novas modalidades transacionais e uma melhor distribuição dos papéis e funções familiares.

Percebe-se que esse processo de compreensão da história do grupo familiar, de seus elementos, em termos sistêmicos, é diferente de realizar uma anamnese de uma forma fria e impessoal. A problemática de aprendizagem está indissociavelmente ligada a alguns aspectos, a partir da interação do sujeito e das circunstâncias do meio social.

Tendo em vista o objetivo de analisar como os pais lidam com as dificuldades de aprendizagem da criança diante do baixo rendimento escolar, buscou-se identificar e analisar as concepções dos pais acerca da dificuldade dos filhos, percebendo-se que eles não têm clareza de que a dificuldade de aprendizagem, independentemente da sua etiologia, se inicia na família, através de atitudes que inibem a autonomia de raciocínio e a oportunidade de entrar em contato com situações novas e desafiadoras. A literatura indica que alguns problemas de aprendizagem podem ter origem em atitudes que não autorizam os membros da família a fazerem suas próprias escolhas e a terem autoria de pensamento.

Constatou-se que a modalidade de aprendizagem presente na interação entre pais e filhos em situação de ensino-aprendizagem, quando não se autoriza a livre autoria de 
pensamento, se revela na insegurança que a criança apresenta ao raciocinar em termos mais abstratos ou em situações em que deve esconder sua opinião.

A fim de ampliar a análise das questões que envolvem a criança com dificuldade de aprendizagem nas relações familiares, pensamos ser importante desenvolver outras investigações sobre o tema, mas, tendo agora como foco os profissionais que atuam diretamente nas escolas, em particular, os psicopedagogos institucionais. Deste modo, o pesquisador poderá compreender a visão desses profissionais acerca das dificuldades de aprendizagem, assim como os procedimentos e recursos adotados pela escola junto à criança que apresenta tais problemas e à sua família. Acreditamos que encaminhar os alunos com dificuldades de aprendizagem para o consultório dos psicopedagogos, procurando ideais de cura, não pode ser a única alternativa para a escola, para a criança e para a família.

Finalmente, a pesquisa aponta a qualidade da escola, a baixa escolaridade dos pais e o convívio em bairro violento como fatores que podem intervir na dificuldade de aprendizagem e que, portanto, necessitam ser investigados de forma mais aprofundada em estudos futuros.

\section{Referências}

Berenstein, Isidoro. Problemas familiares contemporâneos ou situações familiares atuais. Psicologia USP, v. 13, n. 2, p. 15-25, 2002.

Biasoli-Alves, Zélia; Simionato-Tozo, Stella; Sagim, Mirian. Valores e práticas; permanências e mudanças: estudo de famílias trigeracionais. Família, Saúde e Desenvolvimento, Curitiba, v. 8, n. 1, p. 26-31, jan./abr. 2006.

BITTELBRUNN, Edna; CASTRO, Mary. Sou Pãe! reflexões sobre os pais que educam/criam seus filhos sozinhos. In: MOREIRA, L.; PETRINI, J.; BARBOSA, F. (Org.). O pai na sociedade contemporânea. São Paulo: Edusc, 2010. p. 225-36.

Bleger, José. Simbiose e ambigüidade. 2. ed. Rio de Janeiro: Francisco Alves, 1988. (Série Psicologia e Psicanálise).

Bowlby, John. Apego, perda e separação. São Paulo: Martins Fontes, 1993.

Carvalho, Ana Maria. Em busca da natureza do vínculo: uma reflexão psicoetológica sobre grupos familiares e redes sociais. In: PETRINI, João Carlos; CAVALCANTI. Vanessa (Orgs.). Família, sociedade e subjetividades: uma perspectiva multidisciplinar. Petrópolis, RJ: Vozes, 2005. p. 183-93.

Carvalho, Ana Maria; Politano, Isabella; Franco, Anamelia. Uma reflexão sobre o conceito de vínculo interpessoal na teorização psicológica. In: CARVALHO, Ana Maria; Moreira, Lúcia (Orgs.). Família, subjetividade, vínculos. São Paulo: Paulinas, 2007. p. 126-40. 
Cerveny, Ceneide. A família como modelo: desconstruindo a patologia. Campinas: Livro Pleno, 1994.

Chamat, Leila. Relações vinculares e aprendizagem: um enfoque psicopedagógico. São Paulo: Vetor, 1997.

Chamat, Leila. Técnicas de diagnóstico psicopedagógico: o diagnóstico clínico na abordagem interacional. São Paulo: Vetor, 2004.

Cigoli, Vittorio; Scabini, Eugênia. Family identity: ties, symbols, and transitions. Mahwah: Lawrence Erlbaum Associates, 2006.

Donati, Pierpaolo. Família no século XXI: abordagem relacional. São Paulo: Paulinas, 2008. Faria, Rosely. A função do Jogo Colaborativo na terapia familiar sistêmica. São Paulo: Casa do Psicólogo. 1998, p. 27-34.

LIMA, Taís. A primeira ensinante; mãe e filho e as relações de aprendizagem. São Paulo: Vetor, 2002.

Mauss, Marcel. Ensaio sobre a dádiva: forma e razão da troca nas sociedades arcaicas. In: Mauss, Marcel. Sociologia e Antropologia. São Paulo: Edusp, 1974. v. 2, p. 1923-24.

Muñiz, Ana Maria. Pediatria e Psicopedagogia: parceria na avaliação do desenvolvimento da criança. Revista Psicopedagogia, São Paulo, v. 19, n. 58, 2001.

Petrini, João Carlos. Políticas sociais dirigidas à família. In: Borges, A.; Castro, M. G. (Orgs.). Família, gênero e gerações: desafios para as políticas sociais. São Paulo: Paulinas, 2007. p. 207-31.

Petrini, João Carlos. Notas para uma antropologia da família. In: Petrini, J. C.; Moreira, L. V. C.; Alcântara, M. A. R. (Orgs.). Família XXI: entre pósmodernidade e Cristianismo. São Paulo: Companhia Ilimitada, 2003. p. 71-105.

Pichon Rivière, Enrique. Teoria do vínculo. 7. ed. São Paulo: Martins Fontes, 2007.

Polity, Elizabeth. Dificuldade de aprendizagem e família: construindo novas narrativas. São Paulo: Vetor, 2001.

Polity, Elizabeth. Psicopedagogia, um enfoque sistêmico: terapia familiar nas dificuldades de aprendizagem. São Paulo: Vetor, 2004.

Ramos, Helena; Cunha, Roberto. Fatores de risco para prematuridade: pesquisa documental. Rev. Enferm. v. 13, n. 2, p. 297-304, abr./jun. 2009

Samara, Eni. O que mudou na família brasileira? da colônia à atualidade. Psicologia USP, São Paulo, v. 13, n. 2, 2002. Disponível em: <http://www.scielo.br/ scielo.php?script=sci_arttext\&pid=S0103-65642002000200004>. Acesso em: 20 out. 2011.

Sampaio, Simaia. Manual Prático do Diagnóstico Psicopedagógico Clínico. São Paulo: Halk, 2009. 
Sarti, Cintia. Algumas questões sobre família e políticas sociais. In: JACQUET, Christiane; Costa, Livia. (Org.). Família em mudança. São Paulo: Companhia Ilimitada, 2004. p. 193213.

Scabini, Eugenia; Cigoli, Vittorio. Relación familiar: la perspectiva psicológica. In: Gonzales, M. I. (Org.). El cuidado de los vínculos: mediación familiar y comunitaria. Bogotá:

Universidad del Rosario, 2007. p. 71-106. (Collección Textos de Psicología).

Scabini, Eugenia; Iafrate, Rafaella. Psicologia dei legami familiari. Bologna: Il Mulino, 2003.

Singly, François de. Sociologia da família contemporânea. Rio de Janeiro: FGV, 2007. p. 167-83.

Porcentagem de contribuição de cada autor no manuscrito

Rosa Maria da Motta Azambuja - 100\% 